\title{
FOSTERING POSITIVE ATTITUDES TOWARDS SELF-CARE AMONG THE YOUTH IN BONGOL VILLAGE DURING THE RECOVERY MOVEMENT CONTROL ORDER
}

\author{
Getrude C. Ah Gang ${ }^{1}$, \& Jaimond Lambun² \\ ${ }^{1}$ Faculty of Psychology and Education, University Malaysia Sabah (Malaysia) \\ ${ }^{2}$ Bongol Village Community Council (Malaysia)
}

\begin{abstract}
One of the major concerns among the relevant public authorities during the 2019 coronavirus disease (Covid-19) pandemic is the attitude and behavior of the Malaysian society regarding compliance with self-care Covid-19. Although the number of Covid-19 cases is decreasing, public authorities, such as the Malaysian Ministry of Health continually remind people to adhere to the Standard Operating Procedure (SOP) for Covid-19 to reduce the number of cases. To support the authorities' efforts, a one-day self-care Covid-19 programme involving 10 youths ( 3 males \& 7 females) with a mean age of 17.35 (SD=3.36) was implemented in Bongol village, Tamparuli. To adhere the Covid-19 SOP regulation which prohibits a large number of people from gathering in a confined, crowded and closed spaces, only a few participants were involved. The programme, which was conducted at the Bongol village community hall, involved various organized activities emphasising the three elements of attitude: cognitive, affective, and psychomotor. Before the programme began, all the participants were registered, and their body temperatures scanned to ensure that they were free from any Covid-19 symptoms. Each participant was given a mask and a small bottle of hand sanitiser that could be used throughout the programme. The activities comprised an ice-breaker, a talk on personal self-hygiene, a 20.02-minute self-care video produced by 28 psychology students, personal self-reflections by the participants, a group exercise, a community song, and a two-way discussion on self-care. The Covid-19 self-care programme, implemented with guidance from the Yale Attitude Change Model, emphasizes the practical issue of "who says what to whom and with what effects. The participants' attitude was measured before and after they completed the one-day programme. The results of a Wilcoxon signed-ranked test study showed that there is a significant difference between the participants' pre- and post-study attitudes towards self-care. The study results showed that the Covid-19 self-care programme, which is based on the social psychology approach, can help foster positive youth attitudes towards self-care. In regard to the authorities' efforts to lower the number of Covid-19 cases to zero, it is suggested that each party needs (either governmental and non-governmental agencies) to support the Covid-19 campaign and programme by sharing and delivering self-care messages in creative ways to Malaysian communities, especially those in rural areas.
\end{abstract}

Keywords: Attitude, cognitive, affective, and psychomotor, self-care program.

\section{Introduction}

In January 2020, the World Health Organization (WHO) declared that the Covid-19 outbreak was a public health emergency of international concern and that there was a high risk of it spreading to countries around the world. The spread of the virus caused great concern for the Malaysian public and government. In mid-March, Malaysia had the highest number of Covid-19 cases in Southeast Asia (Asnarulkhadi, Mahazan, Abdul Hadi, \& Siti Rahah, 2020). This forced the Malaysian government to impose the 2020 Movement Control Order (MCO), which began on 18 March 2020 and ended on 28 April 2020. The increase in Covid-19 cases caused the MCO to be upgraded to an Enhancement Control Order, which was in effect from 29 April until 12 May 2020. To ensure that the situation was under control, the government then upgraded it to a Recovery Movement Control Order (RMCO) (Yusof,2020). Within each phase of the $\mathrm{MCO}$, the government and the Malaysian Ministry of Health continuously reminded people to adhere to the Covid-19 standard operating procedures (SOPs), such as washing hands regularly; wearing masks; maintaining a distance of at least one meter from other people; avoiding confined, crowded, and closed spaces; and maintaining a healthy lifestyle. In their efforts to raise public health awareness regarding Covid19 , the authorities should focus on eradicating media manipulation, myths, and information that is not based on scientific facts (Asnarulkhadi et al., 2020). Accurate information and active action by the relevant 
authorities to combat the spread of Covid-19 can help create awareness and cultivate positive attitudes towards self-care among members of society.

People have been practising self-care for thousands of years, and it has been applied mindfully by global societies to deal with the Covid-19 pandemic. The Canadian Mental Health Association recommends self-care as a coping strategy in dealing with the pandemic (Wise, 2020). Physical distancing, good respiratory hygiene, and hand washing are important examples of self-care actions that everyone can take every day to protect against Covid-19. Many other aspects of self-care can make a difference to human health and well-being during the Covid-19 pandemic (Wise, 2020). The ability to care for ourselves can make us feel stronger, more resilient, and better able to care for others, which is what is needed as the world faces the Covid-19 pandemic (Wise, 2020). Maintaining a positive attitude to self-care might be challenging for some people. Some might be hesitant to follow the MCO regulations or may forget to follow the general SOPs because they do not align with their cultural norms and because of psychological reactance. Psychological reactance is a psychological response that occurs when one perceives one's freedom as being threatened, and it often leads to behaviour that is the exact opposite of that which was sought by those who issued the instructions (Steindl, Jonas, Sittenthaler, Traut-Mattausch \& Greenberg, 2015). For instance, some Malaysians ignored the MCO might be because lack awareness regarding the seriousness of the Covid-19 pandemic. This was revealed in Asnarulkhadi et al's study (2020) that 3,211 Malaysians from various backgrounds are unaware of the severity of Covid-19 and its impact on human health. The results revealed that $37 \%$ of the respondents were unaware that CovidD-19 can cause serious infections, such as pneumonia, and $24 \%$ of the respondents did not realise that washing one's hands with soap for 20 seconds can help prevent the spread of the virus. In addition, most Malaysians possess an average level of knowledge and a neutral attitude towards social-distancing practices. Malaysians' lack of awareness about the seriousness of the Covid-19 pandemic might be because they need time to adopt new attitudes, behaviours, and norms.

For many people, self-care does not come naturally nor easily, and it is influenced by numerous factors, such as attitude, knowledge, and awareness (Di Iorio, 2020). Past studies (e.g., Arina et al., 2020; Zhong et al., 2020) revealed that people's attitudes towards self-care have improved significantly due to the Covid-19 pandemic. A study conducted by Zhong et al. (2020) indicated that there is a significant correlation between a higher level of Covid-19 knowledge; more positive attitudes; and, most importantly, the improved adoption and implementation of safety practices during the rapid rise of the outbreak. In regard to rural communities, some might face difficulties in accessing Covid-19 necessities, such as face masks, hand sanitisers, and information about the virus. People in rural areas face different health challenges depending on where they are located (Centre for Disease Control and Prevention, 2020). Throughout the MCO, the Malaysian government took extra effort to provide food supplies and other necessities to the rural areas of Sabah and Sarawak with the assistance of the Malaysian Armed Forces (Daim, 2020). Support in the form of food supplies and necessities from the authorities should be accompanied by the implementation of awareness and attitude programmes and interventions to create more positive attitudes towards self-care among rural people. Past studies (e.g., Nyakarahuka, 2017, Roy et al.,2020) have shown that knowledge and attitude towards self-care are important elements in dealing with pandemic. Individuals' attitudes, knowledge, and awareness play a significant role in the development of habits and self-care. The public health sector could enhance community members' knowledge and attitudes by supplying more educational materials; providing health education on epidemic preparedness; and using appropriate communication channels, as proposed by the community members themselves (Nyakarahuka, 2017), such as the self-care programme that was conducted in Bongol village in collaboration with university students.

\section{Design}

The quasi-experimental study design with a pre- and post-study design which involved 10 participants was used in this study. This method was used because it can examine the effectiveness of the self-care programme. The quasi-experimental study most likely to conducted in field settings in which random assignment is difficult or impossible. (Price,2013). This method resembles experimental research, but it is not true experimental research.

\section{Objectives}

To support and deliver positive messages to the rural community, the self-care programme was implemented in collaboration with the Bongol Village Community Management Council during the RMCO. The aim of the programme is to cultivate a positive attitude towards self-care among the youth in the village, particularly during the COVID-19 pandemic. The self-care programme was implemented on 26 June 2020 and adheres strictly to the COVID-19 SOP regulations. The RMCO was announced by the Malaysian prime minister on 7 June 2020 and was in effect from 10 June 2020 until 31 August 2020, with more lenient restrictions compared to the MCO (Flanders Trade, 2020). 


\section{Methodology}

Ten participants took part in the one-day programme and the pre- and post-studies. They originated from the Bongol village, and their ethnicity was Kadazandusun. There were seven females and three males with a mean age of $17.80(\mathrm{SD}=3.36)$. Letters of permission were granted by the head of the village and the head of the village community management council before we requested permission from the faculty and university. The self-care programme was conducted once the approval letter from the university was released. The program adhered to the Covid-19 SOP regulations, which stipulated that there could be only a small number of participants in the programme. The Covid-19 SOPs also stipulated that private gatherings should be limited to no more than 20 people at any one time during the MCO, and this remained valid during the RMCO (Thomas, 2020).

\subsection{Research instrument}

A set of questionnaires consisting of two parts; demographic profile and attitude towards self-care (i.e., physical and psychological) was distributed. The part A measured participants' demographic information such as ethnicities, ages, education levels, parents' occupations and family health). While for Part B measure Attitude towards self-care (physical and psychological). Attitudes towards self-care comprised caring about physical and psychological aspects, such as having adequate sleep, exercising consistently, understanding mood changes, spending time on self-reflection, showing interest in learning strategies to overcome stress, and seeking to understand the meaning of life in the midst of difficulties. Eight items measured attitudes towards self-care and focused on the three elements of attitude (i.e., emotion, beliefs, \& psychomotor). The scale response was based on a Likert scale ranging from 1 (strongly disagree) to 5 (strongly agree). These items were created by referring to the definition of self-care, self-care scale (e.g., Gonzalez, 2019; Headington Institute, n.d.). The reliability values of the complete set of questionnaires were tested in the pilot study with 32 participants comprising university students, and the reliability values were acceptable (0.72).

\subsection{Results}

Ten participants completed the self-care programme and the pre- and post-study questionnaires. Based on the demographic profile of participants, they came from various academic background. Seven of them are still studying in secondary school and the other three are college and university. Most of the fathers working as farmers and their mothers are housewife. The mean age of the participants in this study was 17.80 years $(\mathrm{SD}=3.36)$. The reliability values for attitudes towards self-care was 0.75 for the pre-study and 0.76 for the post-study, and both values were acceptable (see Table 1). The study showed that there is a significant difference between the pre- and post-studies regarding youth's attitudes towards self-care. The Wilcoxon signed-rank test showed the mean scores for attitudes towards self-care in the pre-study $(\mathrm{M}=31.40, \mathrm{SD}=4.53)$ and post-study $(\mathrm{M}=33.60, \mathrm{SD}=3.72, \mathrm{z}=-2.08, \mathrm{p}=.037)$.

\section{Discussions}

The self-care programme in the Bongol village was implemented during the RMCO. Although the number of Covid-19 cases has decreased, it is important to keep sharing and creating awareness of the importance of physical and psychological self-care, particularly in this rural community, during the pandemic. The study showed that between the pre- and post-study periods, there was a significant difference in participants' attitudes towards self-care: Attitudes were more positive after the participants completed the one-day self-care programme. Various factors might contribute to these positive and significant results, such as the activities that were organised by the 28 students who took the attitude-change course during semester two. The organised activities entailed a brief talk by the organiser on self-care during the Covid-19 pandemic, and this was followed by the delivery of COVID-19 information, self-care talks, and a video presentation by the psychology students. Positive talks and self-care information delivered to participants might influence the cognitive, emotional, and psychomotor elements of attitude. These three elements were thoroughly discussed in the video presentation, which lasted 20.02 minutes. The programme instructor also provided self-reflection question-and-answer sessions, during which participants could thoroughly discuss the content of the video and self-care related to the Covid-19 pandemic. Each activity that was arranged in this programme contributed to the participants' positive thoughts or beliefs about self-care, particularly during the RMCO. This possibly triggered more positive emotions regarding engagement with self-care behaviour and showed greater intentions to perform self-care behaviour, such as exercising consistently every day, getting adequate sleep, spending more time on self-reflection, and learning ways to overcome stress. In regard to changing people's attitudes, all three elements of attitude need to be given attention because they are interrelated. For instance, if participants merely had positive thoughts or beliefs about self-care but showed a lack of intention to perform self-care behaviours, this might 
have affected their overall attitudes towards self-care. To ensure that the attitude-change programme runs well, it is important to refer to the Yale Attitude Change Model (Hovland, Janis \& Kelly,1953), which places emphasis on the practical question "Who says what to whom and with what effect?" In the Bongol village self-care programme, "who" represents university students and lecturers; "says" refers to the self-care messages and activities; "whom" refers to the programme's recipients (i.e., 10 youths in Bongol village); and "what effect" refers to the participants' attention, comprehension, and acceptance, which may yield attitude changes among the participants. During the programme, each participant was provided with a mask and a small bottle of hand sanitiser. The participants were also reminded to wash their hands regularly with the hand-sanitiser gel that was provided in the community hall. In addition, Covid-19 infographics were placed in strategic locations in the community hall. These activities may improve participants' attitudes, awareness, and interest in caring for themselves, and it is hoped that the positive attitudes gained from the programme will remain after the pandemic.

\section{Conclusions}

The active efforts made, and initiative shown by the Malaysian government, combined with the support of the relevant authorities and community, can lead to success if all parties work together to reduce the number of Covid-19 cases to zero and to effectively manage the Covid-19 pandemic. Each party should support the other and continue persuading people to follow the SOPs, such as practising personal self-care and looking out for the people around them. This is because self-care is not only a tool for coping with the pandemic but also about honouring ourselves; in doing so, we say to ourselves and to everyone else, "I matter" (Di Iorio, 2020). Based on Di Iorio's statement, we conclude that the self-care messages are not only shared with the people who are close to us but also with the members of underprivileged communities, who may lack accessibility to Covid-19 information and necessities. During this time, it is important to run self-care and any other programmes related to Covid-19 awareness that may inculcate positive attitudes and behaviours among the members of rural communities. Doing this may help protect Malaysia from Covid-19, which has affected so many people around the globe. These programmes may create more positive attitudes towards self-care, and it is hoped that in the long term, these positive attitudes will remain and will become part of the participants' daily self-care routines after the pandemic.

\section{Acknowledgements}

Our heartfelt appreciation goes to the 10 youth who completed the one-day self-care programme and participated in the study. We also thank the head and committee members of the Bongol Village Community Management Council and the head of Bongol village for supporting the programme and allowing it to be implemented in the village. Our gratitude also goes to the 28 psychology students led by Fariha Gaspar who created the self-care COVID-19 videos. We also thank University Malaysia Sabah for giving us permission to implement the programme during the RMCO, as well as the four volunteers-Musa, Siti Hafizah, Kathijah, and Ruvina-who assisted us during the programme. The generous support and assistance that we received symbolise the community solidarity that is needed to combat the spread of Covid-19.

\section{References}

Arina, A.A., Mohammad Rezal, H., Tham, J.S., Suffian, H.A., \& Emma, M. (2020). Public knowledge, attitudes and practices towards COVID-19: A cross-sectional study in Malaysia, https://doi.org/10.1371/journal.pone.0233668, Retrieved from https://journals.plos.org/plosone/article?id=10.1371/journal.pone.0233668

Asnarulkhadi, A.S., Mahazan, M., Abdul Hadi, S., \& Siti Rahah, H. (2020). Knowledge, attitudes and practice among Malaysians in facing COVID-19 during the implementation of Movement Control Order. Research Square, 1-17, Doi.10.21203/rs.3.rs-35626/v1

Centre for Disease Control and Prevention. (August 3, 2020). Rural community, Retrieved from https://www.cdc.gov/coronavirus/2019-ncov/need-extra-precautions/other-at-riskpopulations/rural-communities.html

Daim, N. (31 March, 2020). Armed forces assess to deliver food, necessities in rural Sabah, Sarawak, Retrieved from https://www.nst.com.my/news/nation/2020/03/579903/armed-forces-assets-deliverfood-necessities-rural-sabah-sarawak

Di Iorio, M.S. (2020). The Importance of Self Care During the Pandemic, https://www.tapinto.net/towns/scotch-plains-slash-fanwood/articles/the-importance-of-self-careduring-the-pandemic 
Flanders Trade. (15 July, 2020). Coronavirus-the situation in Malaysia, Retrieved from https://www.flandersinvestmentandtrade.com/export/nieuws/corona-virus-\%E2\%80\%93-situationmalaysia

Gonzalez,M.J.(2019). An Exploration of Self-Care in Relation to Burnout and Compassion Fatigue Among Social Workers, Retrieved from https://digitalcommons.acu.edu/cgi/view content.cgi? article $=1149 \&$ context $=$ etd

Headington Institute. (n.d). Self-care and lifestyle balance inventory, Retrieved from https://headingtoninstitute.org/files/test_self-care-and-lifestyle-inventory_best_76305.pdf

Hovland, C.I., Janis,I.L., \& Kelley,H.H.(1953).Communication and persuasion: Psychological studies of opinion change, New Haven:Yale University Press

Ilesanmi, O., \& Alele, F.O. (2014). Knowledge, attitude and perception of Ebola virus disease among secondary school students in Ondo State, Nigeria. currents. outbreaks. 4, 8, doi: 10.1371/currents.outbreaks.c04b88cd5cd03cccb99e125657eecd76

Nyakarahuka, L. (2017). Knowledge and attitude towards Ebola and Marburg virus diseases in Uganda using quantitative and participatory epidemiology techniques, PLoS Neql Trop (2017). doi: 10.1371/journal.pntd.0005907

Price, C.P. (2013). Research methods of psychology, California State University

Steindl, C., Jonas, E., Sittenthaler, S., Traut-Mattausch, E., \& Greenberg, J. (2015). Understanding psychological reactance: New developments and findings, Zeitschrift Fur Psychologie, 223(4): 205-214. doi: 10.1027/2151-2604/a000222

Thomas, J. (2020). Restriction on number of visitors to 29 still applies, says Ismail Sabri, Free Malaysia News (FMT), Retrieved from https://www.freemalaysiatoday.com/category/nation/2020/06/13/restriction-on-number-of-visitorsto-20-still-apply-says-ismail-sabri/

Wikipedia (2020). Malaysia movement control order, https://en.wikipedia.org/wiki/2020_Malaysia_movement_control_order

Wise, A. (April 22, 2020). Why self-care is important during COVID-19 especially for health care workers. https://healthydebate.ca/2020/04/topic/pandemic-self-care

World Health Organisation (2020). Mental health and psychosocial considerations during the COVID-19 outbreak, https://www.who.int/docs/default-source/coronaviruse/mental-healthconsiderations.pdf?sfvrsn $=6 \mathrm{~d} 3578$ af 2

World Health Organization (WHO). (12 June, 2020). Self-care during covid-10. https://www.who.int/news-room/photo-story/photo-story-detail/self-care-during-covid-19

Yusof, A. (28 August, 2020). Malaysia's recovery movement control order extended to Dec 31, tourists still not allowed in: PM Muhyiddin. Retrieved from https://www.channelnewsasia.com/news/asia/malaysia-recovery-movement-control-orderextended-dec-31-mco-13047724

Zhong, B., Luo, W., Li, H., Zhang, Q., Liu X., Li, W., Li, Y. (2020). Knowledge, attitudes, and practices towards COVID-19 among Chinese residents during the rapid rise period of the COVID-19 outbreak: a quick online cross-sectional survey, International Journal of Biological Sciences,16(10), 1745-1752. Retrieved from https://www.researchgate.net/publication/340087133 Knowledge attitudes and practices toward s_COVID-19_among_Chinese_residents_during_the_rapid_rise_period_of the_COVID19 _outbreak_a_quick_online_cross-sectional_survey [accessed Jan 16 2021]. 